\title{
The Mental Health Implications of a Local Epidemic: Early Experience with the COVID-19 Outbreak in Wuhan, China
}

\author{
Feiyi Zhang1, Yijia Jessica Li², Limei Zhou ${ }^{3}$, Lepei Gao ${ }^{3}$, Hong $\mathrm{Li}^{3}$, Le $\mathrm{Qi}^{4}$, Fahui Yang ${ }^{3 *}$ \\ ${ }^{1}$ Youth League Committee of Southwest University, Chongqing, China \\ ${ }^{2}$ Department of Psychology, University of Calgary, Calgary, Canada \\ ${ }^{3}$ Faculty of Psychology, Southwest University, Chongqing, China \\ ${ }^{4}$ Chongqing City Management College, Chongqing, China \\ Email: *echozfy@126.com
}

How to cite this paper: Zhang, F., Li, Y. J., Zhou, L., Gao, L., Li, H., Qi, L., \& Yang, F. (2021). The Mental Health Implications of a Local Epidemic: Early Experience with the COVID-19 Outbreak in Wuhan, China. Psychology, 12, 107-119.

https://doi.org/10.4236/psych.2021.121007

Received: December 17, 2020

Accepted: January 18, 2021

Published: January 21, 2021

Copyright $\odot 2021$ by author(s) and Scientific Research Publishing Inc. This work is licensed under the Creative Commons Attribution International License (CC BY 4.0).

http://creativecommons.org/licenses/by/4.0/

\begin{abstract}
Purpose: This article presents national survey data related to the mental health of participants $(N=13,824)$ from every province in the People's Republic of China, in the period of early February, during the early days of the outbreak of the COVID-19 virus. The goal was to examine stress and anxiety levels, even as the virus was spreading across the country. This goal was facilitated by data collected specifically from Wuhan city, which was the geographical epicenter of the outbreak, Hubei, the province in which Wuhan is located, and the rest of China. Methods: The survey included a series of validated measures of mental health, as well as measured constructs such as stress and anxiety, depression, sleep, workplace wellness and social cohesion. To the extent possible, the measures had been previously validated in China and were available in Simplified Chinese, although some measures were created for the unique characteristics of the viral outbreak. The survey was distributed electronically through a network of researchers. Results: The measures were generally reliable, with expected inter-correlations. The factor structure of the Symptom Checklist-90 items was generally consistent with its conceptual dimensions. Mostly importantly, the study revealed a gradient of mental health outcomes, with participants from the city of Wuhan having the highest scores on most mental health measures, with the great Hubei province similar or slightly lower, and the rest of China having elevated, but lower scores on most outcomes. Sleep disturbance also revealed a similar gradient, with participants in the epicenter reporting the most sleep disturbance. Discussion: These results reveal the ability to capture the mental health of citizens during a viral outbreak, and the sensitivity of measures to the mental challenges such
\end{abstract}


an outbreak brings. The gradient of responses revealed the spreading effect of the COVID-19 outbreak, and suggests that worse mental health is highly likely to be an outcome as a pandemic spreads. These results suggest that health officials need to attend to not only the physical and direct effects of a viral pandemic, but also to the importance of the mental health of their citizens.

\section{Keywords}

Mental Health, Local Epidemic, COVID-19, Wuhan

\section{Introduction}

In the context of a global viral pandemic, there is necessarily a primary focus on issues such as rates of transmission of the virus, strategies to reduce the spread of infection, efforts to produce vaccines, and methods to respond to the physical consequences of becoming ill. At the same time, the psychological and social effects of viral outbreaks are enormous, including anxiety about becoming ill, stress related to lost earnings or interrupted education, the psychosocial effects of social isolation, and high perceived threat associated with the frequent amount of media attention given to the epidemic (Kamara et al., 2017; Taha et al., 2013). It is likely that rates of anxiety will increase during major health events (Mollica et al., 2004), but these issues rarely have the opportunity to be studied while the event is in progress.

The current study is the first major survey of mental health outcomes associated with the COVID-19 coronavirus outbreak. This outbreak began in Wuhan city, in the province of Hubei, in the People's Republic of China. Hubei province is situated in South Central China. The first reports of this virus emerged in December 2019, and on January 11, 2020 the first known death from the viral outbreak was identified, although by this time it is likely that dozens of people had been infected. Despite strong and immediate reactions by the health officials in China, cases had been confirmed in a variety of countries by January 20, 2020 including Japan, South Korea, and Thailand. On January 23 the city of Wuhan was isolated by Chinese authorities, and on January 30 the World Health Organization declared a "public health emergency of international concern". As early as February 10 the number of confirmed cases of infection in China had risen to over 40,000, and travel restrictions had been put in place throughout Hubei province. By March 11 the World Health Organization declared an international pandemic.

Since the early dates of the pandemic, the COVID-19 virus has spread globally, with increasing numbers of countries affected and a growing toll in the form of health problems, deaths, economic downturn, and the closure of enormous numbers of businesses, industries, schools, postsecondary institutions, other agencies, and even countries. As of the writing of this article, new social, eco- 
nomic and health implications of the COVID-19 pandemic continue to emerge, and the final cost to the global economy and social world remains to be estimated.

Even though the COVID-19 pandemic continues to grow, significant efforts have already been expended to understand its complex effects. The current study was an effort to understand the psychological aspects of the epidemic in its early stages. A group of researchers based in China organized and rapidly deployed a survey of community members throughout the country, during the period of February 4-14, 2020. As such, the time period for this study happened just as the travel restrictions throughout Hubei province were being enacted, and after the first few cases of COVID-19 had emerged in other countries, but before the full-blown spread of the virus was known, even within China. The information in the current article represents the results of that investigation. No specific hypotheses were generated with respect to the epidemic (as it was at that time), although it was anticipated generally that rates of anxiety and stress would be relatively high. There was also a prediction, given the early assessment of concerns about the virus, that these rates might be higher in Wuhan city than the broader Hubei province, and that in turn the estimates of psychological problems would be higher in Hubei province than the rest of China. As such, the data were analyzed with these three geographical regions in mind. The goal of this article was to examine stress and anxiety levels, even as the virus was spreading across the country.

\section{Method}

Given the desire to rapidly deploy a survey, the primary strategy that was adopted was to use validated measures related to stress and anxiety. These measures were supplemented by others that were created for the unique aspects of the current study. For example, as there was no validated measure of pandemic concerns, several specific questions were written which asked about participants' fears about viral infection. Finally, several items were incorporated into the survey that assessed issues related to work fatigue and social support.

\subsection{Participants}

In order to rapidly deploy the survey, the study relied on convenience sampling. The study was initiated in Chongqing, China through a group of researchers there, and they used their social network to invite researchers from around the country to participate in the survey. A minimum of 100 surveys were collected from each of the 31 provinces and municipalities throughout the People's Republic of China. As most researchers had relatively easy access to university students, these became the primary type of participants. In other provinces, however, some researchers have access to email lists of adults from a wider range of employment categories, and so they were also invited to take part in the survey. In total, 14,283 surveys were collected, although when missing data was consi- 
dered $13,822(96.77 \%)$ of the questionnaires were deemed to be valid.

\subsection{Measures}

\subsubsection{Symptom Checklist-90 (SCL-90)}

The SCL-90 (Derogatis et al., 1973) is a widely used measure of psychopathology in clinical populations as well as psychiatric symptoms in general populations. The SCL-90 contains 90 self-report questions organized into nine symptom sub-scales of Somatization, Obsessive-Compulsive, Interpersonal Sensitivity, Depression, Anxiety, Hostility, Phobic-Anxiety, Paranoid Ideation, and Psychoticism. Each question is rated on a 5-point Likert scale from 0 (not at all) to 5 (extremely), with higher scores indicating higher symptomatology (Zhang \& Zhang, 2013; Agüera et al., 2017). The SCL-90 has been translated and validated in Chinese populations (Wang, 1984; Jin et al., 1986; Tang et al., 1999; Feng \& Zhang, 2011). In this study, only the Somatization, Depression, and Anxiety sub-scales were administered to participants.

\subsubsection{Fear Scale}

The Fear Scale is a self-report measure written for the current study that assessed participants' subjective level of fear toward the novel COVID-19 virus and the epidemic. Items assessed the degree to which participants felt distressed when thinking about the epidemic's progression, media reports of the epidemic, or possibly being infected with COVID-19. The scale consisted of eight items that ranged from 1 (completely disagree) to 5 (completely agree). Higher scores indicated higher subjective levels of fear.

\subsubsection{Guilt Proneness Scale (GP-5)}

The GP-5 (Cohen et al., 2014) used in the current study was modified from the Guilt and Shame Proneness Scale (GASP) (Cohen et al., 2011). The GP-5 assessed proneness to feelings of guilt. Each of the 5 items presents a private transgression that respondents could face in daily life (e.g., having been given too much change by store clerk). Respondents indicate their likelihood of responding in a certain manner from 1 (Extremely Unlikely) to 5 (Extremely Likely), with higher scores indicating higher guilt proneness. The GASP has demonstrated construct validity and invariance in a Chinese sample (Young et al., 2019).

\subsubsection{Stanford Acute Stress Reaction Questionnaire (SASRQ)}

The SASRQ (Cardena et al., 2000) is a self-report measure of the presence of acute stress disorder (ASD) symptoms, as outlined in the DSM-IV guidelines. Potential symptoms include dissociation, re-experiencing trauma, avoidance, anxiety and hyperarousal, and impaired functioning following a specific incident or time period. The SASRQ consists of 30 items scored on 6-point Likert scales ranging from 0 (no experience) to 5 (very often experienced). Scores range from 0 to 150 , with scores greater than 40 indicating moderate ASD and scores greater than 57 indicating severe ASD. The SASRQ has good psychometric properties in 
Western populations, and a Korean version has shown good reliability and validity (Kweon et al., 2013).

\subsubsection{Post-Traumatic Stress Disorder Checklist-Civilian Version (PCL-C)} The PCL-C (Weathers et al., 1993) is a widely used self-report measure of the DSM-IV post-traumatic stress disorder (PTSD) symptom sub-scales of re-experiencing, avoidance or numbing, and increased arousal. The PCL-C consists of 17 items scored on 5-point Likert scales from 1 (not at all) to 5 (extremely). Scores range from 17 - 85, with higher scores indicating more severe PTSD symptoms. Scores of 38 - 49 indicate a certain degree of PTSD symptoms, and a score of 50 suggests a PTSD diagnosis (Yin et al., 2018). The Chinese version of the PCL-C has excellent internal consistency and convergent validity (Yang et al., 2007).

\subsubsection{Work Fatigue Scale}

The Work Fatigue Scale was developed for the current study, and assessed the degree to which individuals felt exhausted, experienced concentration difficulties, a dampened sense of achievement, and job burnout related to their work. The scale contained 17 items, each rated on a 5-point Likert scale from 1 (completely disagree) to 5 (completely agree). Higher scores indicate increased levels of work fatigue.

\subsubsection{Oslo 3-Item Social Support Scale (OSS-3)}

The OSS-3 (Dalgard et al., 1995) is widely used in Europe to measure perceived social support. It has three items: the number of people to whom the respondent felt close, whether others show interest or care to the respondent, and the ease obtaining practical support from others. Scores suggest poor (2 - 8), moderate (9 - 11), or strong (12 - 15) social support. The OSS-3 has sufficient reliability and validity in a non-Western population (Abiola et al., 2013).

\subsubsection{Brief Sleep Diary}

Participants were also instructed to complete a sleep diary that tracked sleep duration and quality over the past month. Sleep duration was scored from 0 (greater than or equal to 7 hours of sleep) to 3 points (less than 5 hours of sleep). Sleep quality was rated from 1 (poor) to 3 (excellent), and these ratings are included in the current study.

\subsection{Procedure}

Ethics approval for this study was obtained from Southwest University, in Chongqing, the People's Republic of China. The anonymous survey employed in the current study was sent out using a web-based platform that administers surveys, entitled Questionnaire Star. This platform allowed for participants to respond with different interfaces, including WeChat, cellphone and Hyperlink. WeChat is a widely used communication program in China, which permits both web-based and smart phone interactions. The instructions for the study read: "The 
occurrence of a major life event, due to its suddenness and its disastrous impact, will inevitably cause many people to have different psychological and physical effects. These events will trigger the body's stress response, and bring negative emotions, confusion, and other reactions. In order to scientifically evaluate the impact that the novel coronavirus has had on you, please read the instructions carefully. Once you understand the instructions, please answer based on your own experiences. All of your answers will be kept strictly confidential, and personal information will not be disclosed. Thank you for your cooperation! When you experience or witness an unpredictable event, the consequences of this event will affect your mental and physical state to a certain extent. Please evaluate this event truthfully, based on your own condition at this moment."

\section{Results}

The characteristics of the 13,824 final participants for this study can be found in Table 1 . Approximately $72 \%$ of the sample was female. The large majority of participants were involved in undergraduate university education (almost 82\%), largely as a result of the fact that the survey was primarily distributed in universities, and almost $80 \%$ of the respondents were students. This said, there were

Table 1. Sample characteristics $(N=13,824)$.

\begin{tabular}{|c|c|c|c|}
\hline & able & $N$ & $\%$ \\
\hline \multirow{2}{*}{ Gender } & Male & 3.903 & 28.2 \\
\hline & Female & 9.919 & 71.8 \\
\hline \multirow{3}{*}{ Geographical location } & Wuhan City & 313 & 2.3 \\
\hline & Hubei province (not Wuhan) & 489 & 3.5 \\
\hline & Rest of China & 13.022 & 94.2 \\
\hline \multirow{3}{*}{ Survey method } & WeChat & 8.955 & 64.8 \\
\hline & Cell-phone & 4.767 & 34.5 \\
\hline & Hyperlink & 100 & 0.7 \\
\hline \multirow{4}{*}{ Education } & Junior high school or less & 1025 & 7.4 \\
\hline & High school/vocational & 1092 & 7.9 \\
\hline & Undergraduate education & 11.307 & 81.8 \\
\hline & Graduate school & 398 & 2.9 \\
\hline \multirow{7}{*}{ Occupational Group } & Student & 10.986 & 79.5 \\
\hline & Professional/technical & 539 & 3.9 \\
\hline & Government/public service & 473 & 3.4 \\
\hline & Medical & 392 & 2.8 \\
\hline & Retail/commercial worker & 256 & 1.9 \\
\hline & First responder & 171 & 1.2 \\
\hline & Other & 1.005 & 7.3 \\
\hline
\end{tabular}


relatively large numbers of other employment groups included in the survey, including professional and technical workers, government and public service workers, and medical employees. Table 1 also reveals that respondents predominantly used either WeChat or simple cell phone interface to complete the survey. Finally, it can be seen in Table 1 that there was representation from Wuhan City, the greater Hubei province, and the rest of China.

Prior to between group analyses of the three geographical regions, two preliminary analyses were conducted. First, in order to have confidence that the Symptom Checklist was accurately measuring the intended constructs, a factor analysis of the SCL items was conducted. Table 2 presents the rotated factor structure of the SCL items that were studied, and these results generally supported a three-factor solution. In particular, the items intended for the somatization factor loaded almost uniquely and clearly on this dimension, whereas the depression and anxiety items tended to have cross loadings, although the depression items all had higher loadings on the depression scale, and the anxiety items all had higher loadings on the anxiety scale. It is widely recognized that anxiety and depression are commonly correlated constructs, so the latter cross loading is not deemed to be a significant threat to the validity of the SCL.

The second preliminary analysis was the computation of internal reliability coefficients and correlations among the various dependent variables. As can be seen in Table 3 all of the scales had moderate to very high internal reliabilities, as the coefficient alpha ranged from 0.76 the 3 -item Oslo scale to 0.97 for the Stanford Acute Stress Questionnaire. Table 3 also presents correlations among the different variables. Given the extremely large sample size employed in this study, it should be recognized that even small correlations were likely to be statistically significant. This pattern was observed, as most correlations were statistically significant. Globally, the measures that reflected increased stress, anxiety or mental health symptoms correlated positively and significantly with each other. In contrast, the Oslo Scale of Social Support was negatively correlated with the mental health measures. The guilt scale had a pattern of lower levels of correlation with most of the other variables.

The primary analyses for this study are shown in Table 4 . This table presents the means and standard deviations, and analyses of variance for the primary dependent variables, as a function of geographical setting. Comparisons are provided between Wuhan City, Hubei province and the rest of China. All ANOVAs revealed significant group differences, with the exceptions of the Work fatigue scale and the Oslo scale. Participants in Wuhan city had significantly higher levels of acute stress trauma, symptoms of somatization, depression and anxiety, fear and guilt than participants in the rest of China. For some of these variables, participants in Wuhan city also had higher scores than participants in other parts of Hubei province (SCL anxiety, and the Fear and Guilt scales), but on other variables including the Acute Stress Scale, the Trauma scale and the SCL dimensions of somatization and depression there was no significant difference between participants in Wuhan city and Hubei province. 
Table 2. Rotated factor structure of the SCL items.

\begin{tabular}{|c|c|c|c|}
\hline Item & Factor I & Factor II & Factor III \\
\hline Som1-Headache & - & - & 0.58 \\
\hline Som2-Dizziness or fainting & - & - & 0.51 \\
\hline Som3-Chest soreness & - & - & 0.52 \\
\hline Som4-Back soreness & - & - & 0.6 \\
\hline Som5-Nausea or upset stomach & - & - & 0.59 \\
\hline Som6-Muscle pain & - & - & 0.65 \\
\hline Som7-Difficulty breathing & - & - & 0.49 \\
\hline Som8-Periodically feeling cold or hot & - & - & 0.51 \\
\hline Som9-Body tingling or stinging & - & - & 0.56 \\
\hline Som10-Blocked/clogged sensation in throat & - & - & 0.53 \\
\hline Som11-Weakness in some part of the body & - & - & 0.66 \\
\hline Som12-Feeling heaviness in hands or feet & - & - & 0.6 \\
\hline Dep1-Decreased interest in sex & 0.54 & - & - \\
\hline Dep2-Feel less energetic and move slower & 0.63 & - & 0.34 \\
\hline Dep3-Want to end your own life & 0.44 & - & - \\
\hline Dep4-Crying easily & 0.51 & 0.31 & - \\
\hline Dep5-Feel trapped, or like someone wants to capture you & 0.28 & 0.48 & - \\
\hline Dep6-Frequently blame yourself & 0.58 & 0.41 & - \\
\hline Dep7-Feel lonely & 0.68 & - & - \\
\hline Dep8-Feel depressed & 0.68 & 0.34 & - \\
\hline Dep9-Excessive worry & 0.55 & 0.48 & - \\
\hline Dep10-Not interested in anything & 0.72 & - & - \\
\hline Dep11-Hopelessness & 0.75 & - & - \\
\hline Dep12-Feel like everything is difficult & 0.72 & 0.33 & - \\
\hline Dep13-Feel worthless & 0.72 & - & - \\
\hline Anx1-Neurotic, uneasy on the inside & 0.5 & 0.54 & - \\
\hline Anx2-Trembling & - & 0.58 & - \\
\hline Anx3-Feel scared for no reason & 0.3 & 0.72 & - \\
\hline Anx4-Feel afraid & 0.4 & 0.48 & - \\
\hline Anx5-Heart beating hard & - & 0.62 & - \\
\hline Anx6-Feel nervous; get nervous easily & 0.34 & 0.65 & - \\
\hline Anx7-Spells of fear or panic & - & 0.77 & - \\
\hline Anx8 -Feel fidgety or ill at ease & 0.33 & 0.65 & - \\
\hline Anx9-Familiar things seem unfamiliar or unreal & 0.38 & 0.54 & - \\
\hline Anx10-Feel like you need to get things done quickly & 0.36 & 0.35 & - \\
\hline
\end{tabular}

Note: Extraction method was principal component analysis, with Varimax rotation. Only factor loadings of $\geq 0.30$ are shown. Rotation converged in 6 iterations. 
Table 3. Scale reliabilities (in bold on diagonal) and intercorrelations.

\begin{tabular}{|c|c|c|c|c|c|c|c|c|c|}
\hline Variable & $\begin{array}{c}\text { Stanford } \\
\text { stress score }\end{array}$ & $\begin{array}{l}\text { PTSD } \\
\text { score }\end{array}$ & $\begin{array}{l}\text { Oslo } \\
\text { score }\end{array}$ & $\begin{array}{c}\text { SCL } \\
\text { Somatization } \\
\text { Scale }\end{array}$ & $\begin{array}{c}\text { SCL } \\
\text { Depression } \\
\text { Scale }\end{array}$ & $\begin{array}{c}\text { SCL } \\
\text { Anxiety } \\
\text { Scale }\end{array}$ & $\begin{array}{l}\text { Fear } \\
\text { Scale }\end{array}$ & $\begin{array}{l}\text { Guilt } \\
\text { Scale }\end{array}$ & $\begin{array}{c}\text { Work } \\
\text { Fatigue Scale }\end{array}$ \\
\hline Stanford stress score & 0.97 & & & & & & & & \\
\hline PTSD score & $0.82^{* *}$ & 0.86 & & & & & & & \\
\hline Oslo score & $-0.32^{\star *}$ & $-0.31^{\star *}$ & 0.76 & & & & & & \\
\hline SCL Somatization Scale & $0.37^{\star *}$ & $0.35^{\star *}$ & $-0.16^{\star \star}$ & 0.82 & & & & & \\
\hline SCL Depression Scale & $0.56^{\star *}$ & $0.56^{* *}$ & $-0.30^{\star \star}$ & $0.46^{* *}$ & 0.9 & & & & \\
\hline SCL Anxiety Scale & $0.54^{* *}$ & $0.54^{* *}$ & $-0.23^{\star \star}$ & $0.48^{* *}$ & $0.77^{\star *}$ & 0.88 & & & \\
\hline Fear Scale & $0.44^{* *}$ & $0.36^{* *}$ & $-0.18^{\star \star}$ & $0.26^{* *}$ & $0.34^{* *}$ & $0.40^{* *}$ & 0.92 & & \\
\hline Guilt Scale & $0.15^{\star *}$ & $0.12^{* *}$ & $0.02^{*}$ & $0.04^{* *}$ & $0.06^{* *}$ & $0.07^{\star *}$ & $0.23^{* *}$ & 0.94 & \\
\hline Work Fatigue Scale & $0.44^{\star *}$ & $0.41^{\star \star}$ & $-0.41^{\star \star}$ & $0.26^{\star *}$ & $0.42^{\star *}$ & $0.34^{* *}$ & $0.34^{\star *}$ & 0.01 & 0.81 \\
\hline
\end{tabular}

Note: ${ }^{\star}$ Correlation is significant at $p<0.05,2$ tailed; ${ }^{*}$ Correlation is significant at $p<0.01,2$-tailed. Legend: (1) Acute Stress: Stanford Acute Stress Questionnaire; (2) PTSD: Post Traumatic Stress Disorder scale; (3) SCL: Symptom Check List; (4) OSLO: Oslo Scale of Social Support.

Table 4. Primary outcomes.

\begin{tabular}{cccccccc}
\hline \multirow{2}{*}{ Variable } & \multicolumn{2}{c}{$\begin{array}{c}\text { Wuhan City } \\
(N=313)\end{array}$} & \multicolumn{2}{c}{$\begin{array}{c}\text { Hubei Province } \\
(N=489)\end{array}$} & \multicolumn{2}{c}{$\begin{array}{c}\text { Rest of China } \\
(N=13,022)\end{array}$} & \multirow{2}{*}{$F$-Test } \\
\cline { 2 - 6 } & Mean & $S D$ & Mean & $S D$ & Mean & $S D$ & \\
\hline Acute Stress & $25.06^{\mathrm{a}}$ & 27.95 & $22.95^{\mathrm{a}}$ & 23.1 & $19.90^{\mathrm{b}}$ & 23.68 & $10.76^{* * *}$ \\
\hline PTSD Score & $26.37^{\mathrm{a}}$ & 11.3 & $25.56^{\mathrm{a}}$ & 9.58 & $24.23^{\mathrm{b}}$ & 9.61 & $11.67^{* * *}$ \\
\hline Somatization & $13.63^{\mathrm{a}}$ & 2.78 & $13.48^{\mathrm{a}}$ & 2.47 & $13.16^{\mathrm{b}}$ & 2.35 & $9.48^{* * *}$ \\
SCL Depression & $17.17^{\mathrm{a}}$ & 6.42 & $16.44^{\mathrm{a}}$ & 5.11 & $15.70^{\mathrm{b}}$ & 4.92 & $18.43^{* * *}$ \\
Anxiety & $12.94^{\mathrm{a}}$ & 4.49 & $11.83^{\mathrm{b}}$ & 2.89 & $11.35^{\mathrm{c}}$ & 2.97 & $47.87^{* * *}$ \\
\hline Fear Scale & $17.24^{\mathrm{a}}$ & 8.48 & $15.87^{\mathrm{b}}$ & 7.23 & $14.76^{\mathrm{c}}$ & 7.13 & $23.32^{* * *}$ \\
\hline Guilt Scale & $17.50^{\mathrm{a}}$ & 6.6 & $19.59^{\mathrm{b}}$ & 5.08 & $19.30^{\mathrm{c}}$ & 5.41 & $17.49^{* * *}$ \\
\hline Work Fatigue Scale & $36.59^{\mathrm{a}}$ & 11.34 & $36.80^{\mathrm{a}}$ & 10.56 & $37.12^{\mathrm{a}}$ & 10.64 & 0.57 \\
\hline OSLO score & $10.35^{\mathrm{a}}$ & 1.88 & $10.19^{\mathrm{a}}$ & 1.96 & $10.35^{\mathrm{a}}$ & 1.92 & 1.48 \\
\hline
\end{tabular}

Note: ${ }^{* *} p<0.01$. Means with a common superscript are not significantly different, $p<0.05$, using Scheffe's post hoc test. Legend: (1) Acute Stress: Stanford Acute Stress Questionnaire; (2) PTSD: Post Traumatic Stress Disorder scale; (3) SCL: Symptom Check List; (4) OSLO: Oslo Scale of Social Support

Finally, the relationship between location and sleep quality was examined through Chi-squared analysis. The 3-level categorization of sleep quality on the sleep diary was tabulated against the geographical region, and the result yielded a significant result, $\chi^{2}(4)=62.44, p<0.001$. Sleep quality was worse in Wuhan city, as $14.1 \%$ of the sample rated their sleep in the worst category, in comparison to $10.4 \%$ in Hubei province, and $7.8 \%$ in the rest of China.

\section{Discussion}

The purpose of the current study was to examine the psychological aspects of life 
in the People's Republic of China, in the early days of the COVID-19 outbreak. The methodology was a rapid deployment national survey, which yielded data from all of the provinces of China and permitted specific comparisons of groups of participants based on their geographical proximity to Wuhan city, which was the epicenter of the outbreak. Given the very early timeframe of the current survey, the results capture the fact that while anxiety and stress were higher in the province surrounding Wuhan than in the rest of China, participants from $\mathrm{Wu}$ han itself actually had higher levels of distress on some measures than the broader Hubei province. As such, these results represent one of the first clear studies of the spreading psychological impact of a viral infection, as it emerges in one location and spreads throughout a broader geographical area.

Although the results of the study are relatively stark with respect to the psychological effects of an emerging epidemic, it is notable that two domains appeared to be unaffected. One of these was work fatigue, which showed no demonstrable increase in the geographical centre of the COVID-19 outbreak. It is possible that because participants in this area were already starting to have travel restrictions and work limitations, the stress related to work did not vary among sites. On the other hand, while there were mandatory restrictions within Hubei province, these had not yet been extended to all regions of China at the time of the survey. It is therefore possible that the work fatigue measure was insensitive to changes in the work environment, or that work fatigue is truly unaffected by this type of viral break. Further study of this phenomenon is encouraged.

Secondly, it is notable that the social support reported by participants across the country did vary. China is generally considered to be a country with high social contact (Gold et al., 2002) and a collectivist identity (Kolstad \& Gjesvik, 2014; Oyserman et al., 2002). Contemporary methods of social media, and the ability to use multiple communication methods may have led to an outcome whereby social contact remained high, even if the method of communication changed. Unfortunately, the current study did not ask questions related to the methods through which participants engaged in social interaction, and so this question remains important for further study. In particular as community health officials have recommended reduced social contact as a means to slow the spread of the COVID-19 virus, it will be important to examine social connection versus social isolation, and their effects on mental health during the global pandemic.

The results of the current study clearly implicate the importance of the assessment and monitoring of mental health during viral epidemic and pandemics, as has been reported in previous viral and infectious outbreaks (Kamara et al., 2017; Taha et al., 2013; Mollica et al., 2004; IASC, 2015; Tol et al., 2011). The levels of stress, trauma, symptoms of somatization, depression and anxiety, and fear and guilt reported in the current study are all relatively high, and especially for participants who were in proximity to the epicenter of the viral outbreak. As has been shown in other epidemics and humanitarian crises, rates of stress and mental disorder increase (Tol et al., 2011), and in some cases the psychological and social toll of viral infections can be as great or even greater than the physical 
effects themselves. Significant attention is therefore warranted to continue to monitor the psychosocial effects of such outbreaks, and to provide the necessary care and support to affected individuals.

As with any investigation, this study has both strengths and limitations. A primary strength is the immediacy of the study, and the rapid deployment of the survey which allowed for a critical snapshot of the epicenter of the COVID-19 breakout, even as it continued to spread throughout the People's Republic of China, and eventually the world at large. The sample size was large and ensured broad representation of all the provinces of the country. The measures were validated, as much as possible, and thus permitted comparison with existing studies to understand the types of reactions that were observed. On the other hand, a primary limitation of the study was the use of convenience sampling, which resulted in a relatively high percentage of university students as the respondents to the survey. Secondly, as there were no measures for some of the constructs that were being evaluated (e.g. fear specifically related to the spread of the coronavirus), novel items had to be written, which therefore have no known psychometric characteristics.

As the global crisis associated with COVID-19 continues, further study of the psychological and social problems associated with the pandemic is clearly warranted. While the current study suggests a large increase in the amount of stress and anxiety, it is likely that levels of depression and trauma will surge as the pandemic moves from being a coming phenomenon to one that is being lived through, and eventually one that has passed. Further study of the psychological services that are requested by individuals who lived through the viral outbreak will help to establish the negative consequences of this pandemic. Anxiety is maximized in situations with low degrees of predictability, low degrees of controllability, but high personal relevance (Barlow, 2004). Uncertainty and efforts to reduce the catastrophic thoughts associated with anxiety can have a particularly insidious effect on stress and anxiety (Ehlers \& Clark, 2000; Salkovskis, 1999). In this regard, the COVID-19 outbreak is a "triple threat", in that it has all three of the attributes of unpredictability, uncontrollability and high salience in large measure. In an ironical sense, therefore, the outbreak provides an excellent opportunity to study the psychosocial aspects of a global threat, as well as the resiliency of humans to this threat.

\section{Acknowledgements}

The authors would like to acknowledge the following people and institutions, among others, who provided support for this survey. In no particular order, these are: Hunan Normal University, Huaxia Siyuan Psychological Network, Zhejiang Lianxin Technology Co., Ltd., Ling Hui, Yang Qinjun, Xu Piaoran, Yi Kepei, Yao Fei, Li Ke, Lin Yuqing, Tang Man, Liu Shiyu, Xu Muzi, Wu Xiurui, Hu Wen, Yang Ning, Li Yunjie, Xue Shaoyin, Zheng Kaiwen, Hai Yan, Hou Yingping, Jiang La, Zhao Zhengmei, Zhu Youmei, Li Chen, Yu Lili, Zhu Min, Ruan Yufeng, Zhu Jinxiu, Yao Li, Yang Qingshu, Li Xiaolu, Yu Bo, Li Yueqin, 
Xu Liang, Liu Yinshu, Wang Yuling, Zhao Jing, Zhao Yanhua, Ji Jing, Wang Xia, Dong Mei, Hu Jing, Hu Mingli, Yang Li, Chen Jing, Liu Xingchen, Wang Zhengwen, and Wang Huaiqi.

\section{Conflicts of Interest}

The authors declare no conflicts of interest regarding the publication of this paper.

\section{References}

Abiola, T., Udofia, O., \& Zakari, M. (2013). Psychometric Properties of the 3-Item Oslo Social Support Scale among Clinical Students of Bayero University Kano, Nigeria. Malaysian Journal of Psychiatry, 22, 32-41.

Agüera, Z., Brewin, N., Chen, J., Granero, R., Kang, Q., Fernandez-Aranda, F., \& Arcelus, J. (2017). Eating Symptomatology and General Psychopathology in Patients with Anorexia Nervosa from China, UK and Spain: A Cross-Cultural Study Examining the Role of Social Attitudes. PLoS ONE, 12, e0173781.

https://doi.org/10.1371/journal.pone.0173781

Barlow, D. H. (2004). Anxiety and Its Disorders: The Nature and Treatment of Anxiety and Panic. New York: Guilford Press.

Cardena, E., Koopman, C., Classen, C., Waelde, L. C., \& Spiegel, D. (2000). Psychometric Properties of the Stanford Acute Stress Reaction Questionnaire (SASRQ): A Valid and Reliable Measure of Acute Stress. Journal of Traumatic Stress, 13, 719-734.

https://doi.org/10.1023/A:1007822603186

Cohen, T. R., Kim, Y., Jordan, K. P., \& Panter, A. T. (2014). Guilt-Proneness Is a Marker of Integrity and Employment Suitability. Personality and Individual Differences, 92, 109-112. https://doi.org/10.1016/j.paid.2015.12.026

Cohen, T. R., Wolf, S. T., Panter, A. T., \& Insko, C. A. (2011). Introducing the GASP Scale: A New Measure of Guilt and Shame Proneness. Journal of Personality and Social Psychology, 100, 947. https://doi.org/10.1037/a0022641

Dalgard, O. S., Bjork, S., \& Tambs, K. (1995). Social Support, Negative Life Events and Mental Health. The British Journal of Psychiatry, 166, 29-34.

https://doi.org/10.1192/bjp.166.1.29

Derogatis, L. R., Lipman, R. S., \& Covi, L. (1973). Scl-90: An Outpatient Psychiatric Rating scale-Preliminary Report. Psychopharmacology Bulletin, 9, 13-28.

Ehlers, A., \& Clark, D. M. (2000). A Cognitive Model of Posttraumatic Stress Disorder. Behaviour Research and Therapy, 38, 319-345. https://doi.org/10.1016/S0005-7967(99)00123-0

Feng, Z., \& Zhang, D. (2001). Study on the Validity of the Symptom Check-List-90 of Chinese Version. Journal of Third Military Medical University, 23, 481-483.

Gold, T., Guthrie, D., \& Wank, D. (Eds.) (2002). Social Connections in China: Institutions, Culture, and the Changing Nature of Guanxi (Structural Analysis in the Social Sciences). Cambridge: Cambridge University Press.

https://doi.org/10.1017/CBO9780511499579

IASC (2015). Mental Health and Psychosocial Support in Ebola Virus Disease Outbreaks. A Guide for Public Health Programme Planners.

Jin, H., Wu, W., \& Zhang, M. (1986). The Preliminary Results of SCL-90 Analysis in a Chinese Normal Population. Chinese Journal of Nervous and Mental Diseases, 12, 260-263. 
Kamara, S., Walder, A., Duncan, J., Kabbedijk, A., Hughes, P., \& Muana, A. (2017). Mental Health Care during the Ebola Virus Disease Outbreak in Sierra Leone/les soins de sante mentale pendant la flambee de maladie a virus ebola en sierra leone/cuidado de la salud mental durante el brote de la enfermedad del virus del ebola en sierra leona. Bulletin of the World Health Organization, 95, 842-847.

Kolstad, A., \& Gjesvik, N. (2014). Collectivism, Individualism, and Pragmatism in China: Implications for Perceptions of Mental Health. Transcultural Psychiatry, 51, 264-285. https://doi.org/10.1177/1363461514525220

Kweon, Y. S., Jung, N. Y., Wang, S. M., Rauch, S. A., Chae, J. H., Lee, H. K. et al. (2013). Psychometric Properties of the Korean Version of Stanford Acute Stress Reaction Questionnaire. Journal of Korean Medical Science, 28, 1672-1676. https://doi.org/10.3346/jkms.2013.28.11.1672

Mollica, R. F., Cardozo, B. L., Osofsky, H. J., Raphael, B., Ager, A., \& Salama, P. (2004). Mental Health in Complex Emergencies. The Lancet, 364, 2058-2067.

https://doi.org/10.1016/S0140-6736(04)17519-3

Oyserman, D., Coon, H. M., \& Kemmelmeier, M. (2002). Rethinking Individualism and Collectivism: Evaluation of Theoretical Assumptions and Meta-Analyses. Psychological Bulletin, 128, 3-72. https://doi.org/10.1037/0033-2909.128.1.3

Salkovskis, P. M. (1999). Understanding and Treating Obsessive-Compulsive Disorder. Behaviour Research and Therapy, 37, S29-S52. https://doi.org/10.1016/S0005-7967(99)00049-2

Taha, S., Matheson, K., Cronin, T., \& Anisman, H. (2013). Intolerance of Uncertainty, Appraisals, Coping, and Anxiety: The Case of the 2009 h1n1 Pandemic. British Journal of Health Psychology, 19, 592-605. https://doi.org/10.1111/bjhp.12058

Tang, Q; Cheng, A., Yuan, A., \& Deng Y. (1999). Application and Analysis of SCL-90 in China. Chinese Journal of Clinical Psychology, 7, 16-20.

Tol, W. A., Barbui, C., Galappatti, A., Silove, D., Betancourt, T. S., Souza, R. et al. (2011). Mental Health and Psychosocial Support in Humanitarian Settings: Linking Practice and Research. The Lancet, 378, 1581-1591. https://doi.org/10.1016/S0140-6736(11)61094-5

Wang, Z. (1984). Symptom Checklist (SCL-90) (No. 2, 68-70). Shanghai: Shanghai Arch Psychiatry.

Weathers, F. W., Litz, B. T., Herman, D. S., Huska, J. A., \& Keane, T. M. (1993). The PTSD Checklist (PCL): Reliability, Validity, and Diagnostic Utility. The Annual Meeting of the International Society of Traumatic Stress Studies, San Antonio, TX.

Yang, X. Y., Yang, H. A., Liu, Q. G., \& Yang, L. Z.. (2007). The Research on the Reliability and Validity of pcl-c and Influence Factors. China Journal of Health Psychology, 15, 6-9.

Yin, Q., Shang, Z., Zhou, N., Wu, L., Liu, G., Yu, X. et al. (2018). An Investigation of Physical and Mental Health Consequences among Chinese Parents Who Lost Their Only Child. BMC Psychiatry, 18, Article No. 45. https://doi.org/10.1186/s12888-018-1621-2

Young, I. F., Razavi, P., Cohen, T. R., Yang, Q., Alabèrnia-Segura, M., \& Sullivan, D. (2019). A Multidimensional Approach to the Relationship between Individualism-Collectivism and Guilt and Shame. Emotion. (Advance Online Publication) https://doi.org/10.1037/emo0000689

Zhang, J., \& Zhang, X. (2013). Chinese College Students' SCL-90 Scores and Their Relations to the College Performance. Asian Journal of Psychiatry, 6, 134-140. https://doi.org/10.1016/j.ajp.2012.09.009 